Virginia Commonwealth University

vCU Scholars Compass

Ophthalmology Publications

Dept. of Ophthalmology

2017

\title{
Association of Intraocular Pressure With Human Immunodeficiency Virus
}

Matthew T. Young

Virginia Commonwealth University, youngmt2@gmail.com

Rakhi T. Melvani

Virginia Commonwealth University

Faraaz A. Khan

Virginia Commonwealth University

Puneet S. Braich

University of Miami

Surbhi Bansal

Virginia Commonwealth University

Follow this and additional works at: http://scholarscompass.vcu.edu/ophth_pubs

Part of the Ophthalmology Commons

(C) 2017 Elsevier Inc. rights reserved.

\section{Downloaded from}

http://scholarscompass.vcu.edu/ophth_pubs/9

This Article is brought to you for free and open access by the Dept. of Ophthalmology at VCU Scholars Compass. It has been accepted for inclusion in Ophthalmology Publications by an authorized administrator of VCU Scholars Compass. For more information, please contact libcompass@vcu.edu. 


\title{
Association of Intraocular Pressure With Human Immunodeficiency Virus
}

\author{
MATTHEW T. YOUNG, RAKHI T. MELVANI, FARAAZ A. KHAN, PUNEET S. BRAICH, AND SURBHI BANSAL
}

- PURPOSE: Prior studies have shown an association between human immunodeficiency virus (HIV) and reduced intraocular pressures (IOP). The purpose of this study was to determine if patients with HIV on highly active antiretroviral therapy (HAART) had any difference in their IOP compared with patients without HIV or with HIV who are not on HAART.

- DESIGN: Retrospective cross-sectional study.

- METHODS: We included 400 patients from our academic eye center between 2000 and 2016. Group 1 (G1) consisted of patients with HIV on HAART $(n=176)$, Group 2 (G2) consisted of patients with HIV who were not on HAART $(\mathrm{n}=48)$, and Group $3(\mathrm{G} 3)$ consisted of controls without HIV $(n=176)$. An analysis of variance (ANOVA) was performed to compare mean IOP values. Multivariate linear and logistic regression models were performed to assess factors impacting IOP. Difference in IOP was the primary outcome being measured.

- RESUlTs: The mean IOPs in $\mathrm{mm} \mathrm{Hg}$ were $13.7 \pm 5.1$ (G1), $13.1 \pm 3.6$ (G2), and $17.3 \pm 3.8$ (G3), $P<.01$. In regression modeling, having a CD4 count $\leq 700$ cells/ $\mathrm{mm}^{3}$ contributed to a $2.1 \mathrm{~mm} \mathrm{Hg}$ decrease in IOP. Patients with HIV were 7 times more likely to have an IOP $\leq 10 \mathrm{~mm} \mathrm{Hg}$, and patients with a CD4 count $\leq 700$ cells $/ \mathrm{mm}^{3}$ were 13 times more likely to have an IOP $\leq 10 \mathrm{~mm} \mathrm{Hg}$.

- CONCLUSIONS: Absolute CD4 counts may play a role in IOP fluctuations. This association was found in patients with HIV regardless of whether patients were on HAART. (Am J Ophthalmol 2017;176:203-209. (C) 2017 Elsevier Inc. All rights reserved.)

A S OF 2012, THE CENTERS FOR DISEASE CONTROL AND Prevention (CDC) estimates that 1.2 million people in the United States are living with human immunodeficiency virus (HIV). ${ }^{1}$ Estimates of prevalence for all of North America and Western and Central Europe

\footnotetext{
AJO.com Supplemental Material available at AJO.com.

Accepted for publication Jan 20, 2017.

From the Department of Ophthalmology, Virginia Commonwealth University, Richmond, Virginia (M.T.Y., R.T.M., F.A.K., S.B.); Bascom Palmer Eye Institute, University of Miami Miller School of Medicine, Miami, Florida (P.S.B.).

Inquiries to Matthew T. Young, Department of Ophthalmology, Virginia Commonwealth University, 401 N 11th St, Suite 439, Nelson Clinic 4th Floor, Richmond, VA 23298; e-mail: youngmt2@gmail.com
}

elevate this number to 2.4 million individuals. ${ }^{2}$ About $36 \%$ of those with HIV in the United States are currently receiving treatment, and $30 \%$ are successfully keeping their disease under control. ${ }^{1}$ Even with improved education and screening for HIV, as well as improvements in medical therapy, these estimates reveal the continued problem of suboptimal therapy for HIV, which is compounded by lack of access to health care and low health literacy. ${ }^{3-5}$

Modern treatment for HIV infection involves the use of multiple combinations of available antiretroviral therapy (ART), and the current standard of care is for patients to be treated with at least 3 of these medications, termed highly active antiretroviral therapy (HAART). These medications have dramatically altered the prognosis of the disease, and although HIV was once considered a fatal diagnosis, it is now treated as a chronic condition with continued improvement to life expectancy. ${ }^{2}$ This change presents new challenges for healthcare providers as we continue to learn how to manage comorbid conditions in this population.

It is estimated that $50 \%-70 \%$ of HIV-positive patients will develop some type of ocular complication. ${ }^{6}$ When comorbid noninfectious ocular conditions are evaluated, one important area of interest is the diagnosis and treatment of glaucoma, as it has been posited that patients with HIV may have lower intraocular pressure (IOP).

Arevalo and associates ${ }^{7}$ explored this area of study by evaluating IOP in patients with HIV both with and without cytomegalovirus (CMV) retinitis. They compared these populations to a control group without HIV and concluded that patients with HIV had a statistically significantly lower IOP compared with controls. A study by Banker and associates ${ }^{8}$ evaluated aqueous humor dynamics in patients with and without CMV retinitis. They found that HIV was associated with lower aqueous flow rates vs controls independent of CMV status. They concluded from this that the cause of lower IOP in HIV-infected individuals may be related to decreased aqueous production rather than an increase in outflow. Hsu and associates ${ }^{9}$ used reverse-transcriptase polymerase chain reaction (PCR) to measure HIV viral load in plasma and aqueous humor of acquired immunodeficiency syndrome patients with ocular manifestations including CMV retinitis and HIV retinopathy. They noted decreased HIV virus levels in the aqueous in these individuals after initiation of HAART and recovery of T-cell cluster of differentiation 4 (CD4) counts. 
The association between medications used in patients with HIV and changes in IOP is also under investigation. For instance, cidofovir is now a well-documented cause of ocular hypotony. ${ }^{10,11}$ Additionally, Park and associates ${ }^{12}$ performed a retrospective study of IOP in HIV-positive patients on HAART vs controls, and Kozak and associates ${ }^{13}$ performed a longitudinal study of the same relationship. Both groups noted an association between beginning HAART therapy and subsequent normalization of IOP. Although Park and associates did not find an association between CD4 count or viral load and IOP, Kozak and associates noted that both a reduction in T-lymphocyte count and immune recovery defined by a sustained rise in CD4 count were associated with a decrease and increase in $\mathrm{IOP}$, respectively.

The purpose of this study was to evaluate differences in IOP between patients with HIV on HAART, patients with HIV not on HAART, and patients without HIV. To the best of our knowledge, no previous studies have directly compared IOP in HIV-positive patients both on and off HAART therapy. As mentioned previously, only about a third of patients with HIV in the United States are receiving treatment, ${ }^{1}$ providing opportunity to compare IOP in patients on or off HAART. By directly comparing these populations, we can gain a better understanding of the underlying etiology of decreased IOP in these patients. Our secondary aim was to understand what clinical and demographic factors contribute to low IOP readings.

\section{METHODS}

THIS WAS A RETROSPECTIVE OBSERVATIONAL STUDY ON patients with a diagnosis of HIV on or off HAART therapy compared with those without HIV who were treated by the ophthalmology department at a tertiary care academic center from January 2000 to March 2016. Patients were divided into 1 of 3 groups: Group 1 (G1), patients diagnosed with HIV and on HAART; Group 2 (G2), patients with HIV but not on HAART; and Group 3 (G3), patients not diagnosed with HIV and therefore not on HAART. The study was conducted in accordance with the Declaration of Helsinki, and ethical considerations were approved by the institutional review board at the Virginia Commonwealth University health system. This study was approved to be performed as a retrospective study for all groups.

Reasons for patients with HIV not being on HAART included noncompliance, a recent diagnosis of HIV, patients taking time to establish care with an infectious disease provider, or refusal to begin therapy. G3 consisted of patients without the diagnosis of HIV evaluated in Virginia Commonwealth University's comprehensive eye clinic but matched for age, race, and sex to G1.
HIV diagnosis was based on having an evaluation by an infectious disease specialist at our academic center who documented this diagnosis after positive serum test results of anti-HIV antibodies using enzyme-linked immunosorbent assay followed by confirmatory testing with Western blot. A practice pattern in our ophthalmology department is to record the viral load and absolute CD4 count for all patients diagnosed with HIV, allowing monitoring of patients who are at risk for ocular opportunistic infections. We also perform a medical reconciliation via the electronic health record and paper chart to verify which systemic medications patients take. This allowed us to verify which patients were on HAART. Further, patients are questioned about compliance to medication. We also noted demographic data such as age, sex, race, IOP, and family history of glaucoma. IOP measurements were taken by Goldmann applanation tonometry for all groups. Our medical center's laboratory labels a serum sample to have an undetectable viral load if the count is $<20$ copies of HIV RNA particles per mL.

Exclusion criteria consisted of factors that may alter IOP in significant ways. This encompassed a diagnosis of glaucoma, treatment with antiglaucoma medications, active uveitis, prior retinal detachment or retinal hole, history of CMV retinitis, carotid stenosis $>70 \%$, anti-vascular endothelial growth factor injection therapy, systemic carbonic anhydrase inhibitor use, general anesthesia within past 4 weeks prior to IOP measurement, and cannabis use. Exclusion criteria were applied to all 3 groups. A total of 303 potential participants for G1 and G2 were initially screened based solely on having HIV, and 79 participants were excluded based on inclusion and exclusion criteria. This left 176 participants for G1 and 48 for G2. Of those excluded, 42 had a diagnosis of either glaucoma, glaucoma suspect, or ocular hypertension or were on IOP-lowering medication.

Statistical analysis included comparisons of demographic and clinical data to observe differences among groups. Categorical variables were compared by $\chi^{2}$ tests for proportions, and by ANOVA for normally distributed continuous variables and the Kruskal-Wallis test for nonparametric continuous variables. A linear regression model was performed whereby the dependent variable was IOP in the right eye. In this way all patients contributed 1 eye to the analysis. The independent variables were age, race (white, black, Hispanic, or other), sex, CD4 count (either $\leq 700$ cells $/ \mathrm{mm}^{3}$ or $>700$ cells $/ \mathrm{mm}^{3}$ ), viral load (undetectable to 10 000, 10 001-100 000, or over $100000 \mathrm{HIV}$ RNA/mL), group association (G1, G2, or G3), and family history of glaucoma. For the purpose of statistical analysis we assigned a value of 0 for an undetectable viral load. A binary logistic regression model was also performed to determine which factors contributed to a low IOP. In this model the dependent variable was having an IOP $\leq 10$ (yes/no) in the right eye, which provided estimates of odds ratios (ORs). The ORs and 95\% 
TABLE 1. Study Subjects' Demographic and Clinical Information

\begin{tabular}{|c|c|c|c|c|c|}
\hline & $\begin{array}{l}\text { Group 1: HIV on } \\
\text { HAART }(N=176)\end{array}$ & $\begin{array}{l}\text { Group 2: HIV Not on } \\
\text { HAART }(\mathrm{N}=48)\end{array}$ & $\begin{array}{l}\text { Group 3A: Without HIV } \\
\qquad(\mathrm{N}=109)\end{array}$ & $\begin{array}{l}\text { Group 3B: Without HIV, } \\
\text { Hem/Onc }(\mathrm{N}=67)\end{array}$ & $P$ Value \\
\hline Age (mean $\pm \mathrm{SD})$ & $53.5 \pm 7.4$ years & $52.1 \pm 9.6$ years & $53.8 \pm 7.9$ years & $54.1 \pm 9.4$ years & .38 \\
\hline \multicolumn{6}{|l|}{ Race } \\
\hline Non-Hispanic white & $24(14 \%)$ & $13(27 \%)$ & $19(17 \%)$ & $5(21 \%)$ & .03 \\
\hline Non-Hispanic black & 142 (81\%) & $32(67 \%)$ & 86 (79\%) & $56(84 \%)$ & .04 \\
\hline Hispanic & $5(3 \%)$ & $1(2 \%)$ & $3(3 \%)$ & $2(3 \%)$ & .88 \\
\hline Other & $5(3 \%)$ & $2(4 \%)$ & $4(4 \%)$ & $1(1 \%)$ & .61 \\
\hline \multicolumn{6}{|l|}{ Sex } \\
\hline Male & 128 (73\%) & $33(69 \%)$ & $79(72 \%)$ & 49 (73\%) & .59 \\
\hline Female & $41(22 \%)$ & $15(31 \%)$ & $30(28 \%)$ & $18(27 \%)$ & .26 \\
\hline $\begin{array}{l}\text { Absolute CD4 count } \\
\text { (mean } \pm \mathrm{SD})\end{array}$ & $604.3 \pm 211.4 \mathrm{cells} / \mathrm{mm}^{3}$ & $551.6 \pm 270.8$ cells $/ \mathrm{mm}^{3}$ & - & $1084.6 \pm 158.1 \mathrm{cells} / \mathrm{mm}^{3}$ & $<.01^{b}$ \\
\hline \multirow[t]{2}{*}{ Viral load (mean \pm SD) } & $5926.7 \pm 24895.4$ & $40479 \pm 103603.3$ & - & - & $<.01$ \\
\hline & HIV RNA/mL & HIV RNA/mL & & & \\
\hline Undetectable viral load & 96 (55\%) & & & & \\
\hline $\mathrm{IOP}$ right eye (mean $\pm \mathrm{SD})$ & $13.7 \pm 5.1$ & $13.1 \pm 3.6$ & $17.1 \pm 3.2$ & $17.3 \pm 3.8$ & $<.01^{c}$ \\
\hline IOP left eye (mean \pm SD) & $13.3 \pm 5.3$ & $13.3 \pm 3.8$ & $17.0 \pm 3.3$ & $16.9 \pm 4.3$ & $<.01^{c}$ \\
\hline Family history of glaucoma & $31(18 \%)$ & $7(15 \%)$ & $16(12 \%)$ & $6(9 \%)$ & .11 \\
\hline $\begin{array}{l}\text { HAART = highly active an } \\
\text { pressure; RNA = ribonuclei } \\
\text { Note: Actual percentages } \\
{ }^{a} \text { Subset of patients in Gro } \\
\text { which the remainder of the } \\
{ }^{b} \text { Post hoc analysis of varia } \\
\text { each of the groups. } \\
{ }^{c} \text { Post hoc analysis of varia } \\
\text { or Groups } 3 \mathrm{~A} \text { and } 3 \mathrm{~B} \text {. Howe } \\
\text { 3B into a single groups yiel }\end{array}$ & $\begin{array}{l}\text { tiretroviral therapy; Hem/On } \\
\text { were a subset of patients i } \\
\text { may not add up to } 100 \% \text { o } \\
\text { up } 3 \text { who were treated by th€ } \\
\text { control group did not. } \\
\text { nce using Tukey's method in } \\
\text { nce using Tukey's method i } \\
\text { jer, Groups } 3 \mathrm{~A} \text { and } 3 \mathrm{~B} \text { were } \\
\text { Is the same results. }\end{array}$ & $\begin{array}{l}\text { c = Hematology/Oncology } \\
\text { in Group } 3 \text { who were treate } \\
\text { wing to rounding to the nea } \\
\text { Hematology/Oncology ser } \\
\text { dicated that there were sign } \\
\text { ndicated that there was no c } \\
\text { both significantly different c }\end{array}$ & $\begin{array}{l}\text { HIV = human immu } \\
\text { by the acid; SD = } \\
\text { est whole number. } \\
\text { ice and who therefo } \\
\text { ificant differences be } \\
\text { ifference in the mear } \\
\text { ompared to each Grc }\end{array}$ & $\begin{array}{l}\text { hodeficiency virus; IOP = intr } \\
\text { tandard deviation. } \\
\text { e had testing of immune para } \\
\text { tween the mean CD4 values b } \\
\text { IOP values between Groups } \\
\text { up } 1 \text { and } 2 \text {. Collapsing Group }\end{array}$ & $\begin{array}{l}\text { aocular } \\
\text { meters, } \\
\text { etween } \\
1 \text { and } 2 \\
\text { 3A and }\end{array}$ \\
\hline
\end{tabular}

confidence intervals (CIs) were obtained by maximum likelihood estimations, and $P$ values $<.05$ were considered statistically significant. A value of $\leq 10 \mathrm{~mm} \mathrm{Hg}$ was chosen for the IOP, as this was thought to best represent normal episcleral venous pressure, although past studies have shown some variation in this range. ${ }^{14}$ The independent variables were age, race (white, black, Hispanic, or other), sex, CD4 count (either $\leq 700$ cells $/ \mathrm{mm}^{3}$ or $>700$ cells/ $\mathrm{mm}^{3}$ ), viral load (undetectable to $10000,10001-100$ 000 , or over $100000 \mathrm{HIV}$ RNA/mL), group association (G1, G2, or G3), and family history of glaucoma. In both regression models, a backward selection technique was used to eliminate covariates that did not contribute significantly to the fit of the model. All statistical analysis was done with SAS 9.3 (2011; SAS Institute Inc, Cary, North Carolina, USA).

\section{RESULTS}

THERE WAS NO SIGNIFICANT DIFFERENCE IN THE AGE, race, sex, or family history of glaucoma among the groups
(Table 1). There were significantly more white patients in G2 (27\%) compared with G1 (14\%) and G3 (14\%), $P<$.05. Conversely, there were significantly more black patients in G1 and G3 compared with G2 (Table 1). Patients in G3 had the highest absolute CD4 count, which was significantly higher than $\mathrm{G} 1$ and G2. Furthermore, G1 also had a significantly higher value compared with G2 ( $P$ $<.01)$. Only 67 patients in G3 (38\%) had a CD4 level available for comparison because they were concomitantly receiving chemotherapy from the hematology/oncology service and required serum work to monitor their leukocyte and related immune parameters. For illustration purposes this subgroup among the controls was labeled as 3B to reflect treatment by the outpatient hematology/ oncology service at our academic center. These patients were on a wide variety of chemotherapeutic agents, and a total of 12 patients $(18 \%)$ were on T-cell inhibitors and 18 patients $(27 \%)$ were on alkylating agents. G2 had a significantly higher viral load compared with G1 $(P<.01)$. The median value for viral load for $G 1$ was 0 (undetectable), while the median value for G2 was 12 000 HIV RNA/mL. The first 2 groups had high outliers, which skewed their distribution. The range for viral load 


\section{Proportion of All Eyes with Low IOP}

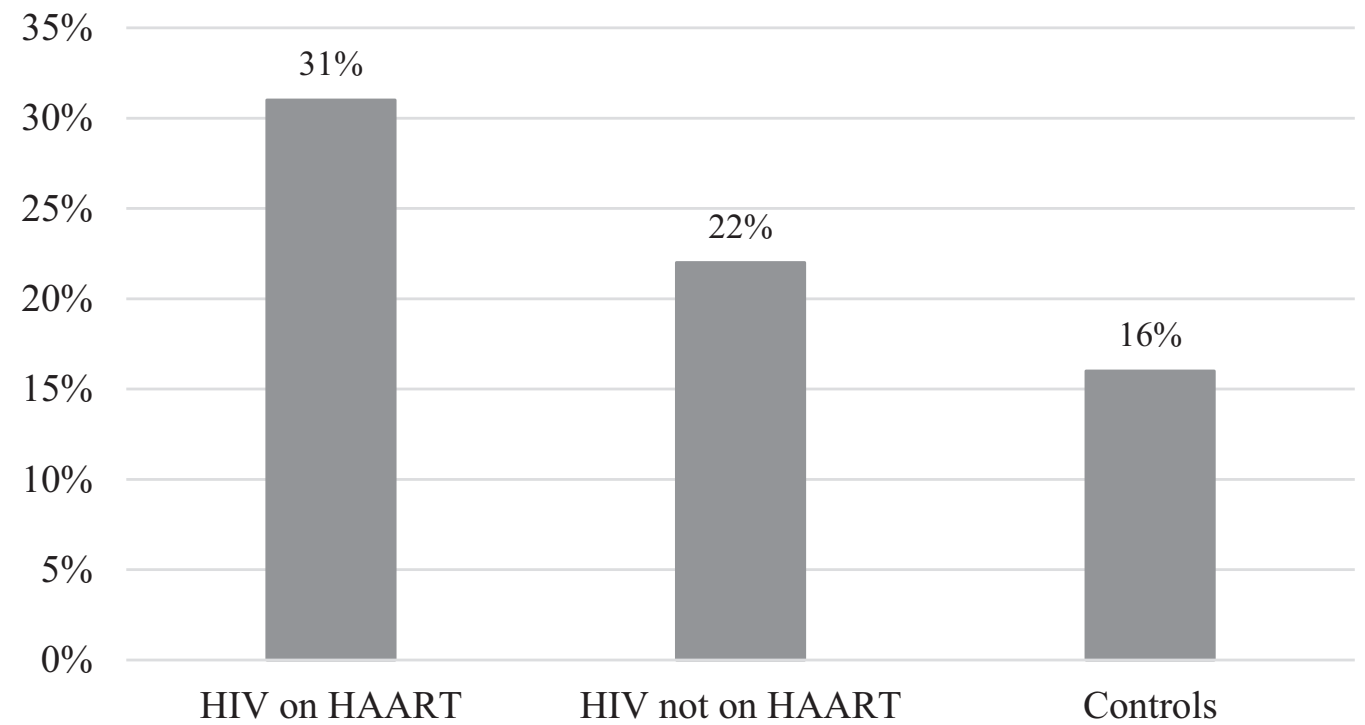

FIGURE 1. Graph showing the distribution of all eyes with intraocular pressure (IOP) $\leq 10 \mathrm{~mm} \mathrm{Hg}$. The proportion among Group 1 (patients with human immunodeficiency virus [HIV] on highly active antiretroviral therapy [HAART]) is significantly higher than both Group 2 (patients with HIV not on HAART) and Group 3 (age- and sex-matched controls without HIV), P < .01. However, Group 2 and Group 3 are not significantly different from each other.

from G1 was undetectable (0) to $220000 \mathrm{HIV}$ RNA/mL, while the range for G2 was 258 to $424000 \mathrm{HIV}$ RNA/ $\mathrm{mL}$. More than half of $\mathrm{G} 1$ had undetectable viral loads. Patients without HIV had significantly higher IOP compared with patients with HIV $(P<.01)$. Among patients with HIV, being on HAART did not significantly change IOP values. The range of IOP values for all eyes was 7$22 \mathrm{~mm} \mathrm{Hg}(\mathrm{G} 1), 6-22 \mathrm{~mm} \mathrm{Hg}(\mathrm{G} 2)$, and 9-23 mm Hg (G3). The IOP was not significantly different in right eyes compared with left eyes for any group. The distribution of all eyes with an IOP $\leq 10 \mathrm{~mm} \mathrm{Hg}$ varied across groups (Figure 1). Among the 352 eyes in G1, 109 had an IOP $\leq 10 \mathrm{~mm} \mathrm{Hg}(31 \%)$, which was significantly higher than the 22\% (21/96) and 16\% (55/352) for G2 and G3, respectively, $P<.01$. G2 and G3 were not significantly different from each other. This figure amalgamates Groups $3 \mathrm{~A}$ and $3 \mathrm{~B}$ because the proportion from each subgroup was similar ( $15 \%$ for $3 \mathrm{~A}$ vs $16 \%$ for $3 \mathrm{~B}$ ) and did not change the overall significance of the comparison.

The only variables significantly affecting the linear regression model (dependent variable being IOP in the right eye) was the CD4 count. Compared with patients with an absolute CD4 count $>700$ cells $/ \mathrm{mm}^{3}$, those with $\leq 700$ cells $/ \mathrm{mm}^{3}$ contributed to a $2.1 \mathrm{~mm} \mathrm{Hg}$ decrease in the intraocular pressure, $P<.01$. The adjusted $R^{2}$ value for this model was 0.19 .

The only variables significantly affecting the logistic regression model for low IOP in the right eye were CD4 count, group association, and male sex (Table 2). Men

\begin{tabular}{|c|c|c|}
\hline \multicolumn{3}{|c|}{$\begin{array}{l}\text { TABLE 2. Factors Impacting Low Intraocular Pressure } \\
\text { Values in the Multivariate Logistic Regression Model }\end{array}$} \\
\hline Variable & Odds Ratio $(95 \% \mathrm{Cl})$ & $P$ Value \\
\hline \multicolumn{3}{|l|}{ Sex } \\
\hline Female & - & \\
\hline Male & $3.0(2.1-4.2)$ & .03 \\
\hline \multicolumn{3}{|l|}{ Group association } \\
\hline Group 3 & - & \\
\hline Group 2 & $6.9(3.9-8.7)$ & $<.01$ \\
\hline Group 1 & $7.3(4.0-9.2)$ & $<.01$ \\
\hline \multicolumn{3}{|l|}{ Absolute CD4 count } \\
\hline$>700$ cells $/ \mathrm{mm}^{3}$ & - & \\
\hline$\leq 700$ cells $/ \mathrm{mm}^{3}$ & $13.4(10.4-17.5)$ & $<.01$ \\
\hline $\begin{array}{c}\mathrm{Cl}=\text { confidence } \\
\text { Nagelkerke } \mathrm{R}^{2}= \\
\text { An intraocular pre } \\
\text { low for the purpose }\end{array}$ & $\begin{array}{l}\text { is model. } \\
10 \text { via applanation } \\
\text { lodel. }\end{array}$ & sidered \\
\hline
\end{tabular}

were at a 3-fold higher odds of having an IOP $\leq 10 \mathrm{~mm}$ $\mathrm{Hg}$ compared with women. Compared with patients without HIV, those with HIV, whether or not they took HAART, had roughly a 7-fold higher odds of having a low IOP. The greatest impact was from the CD4 count. Compared with patients with $>700 \mathrm{CD} 4$ cells $/ \mathrm{mm}^{3}$, those with $\leq 700$ cells $/ \mathrm{mm}^{3}$ have more than a 13 -fold higher odds of having a low intraocular pressure. The Nagelkerke $\mathrm{R}^{2}$ 
IOP

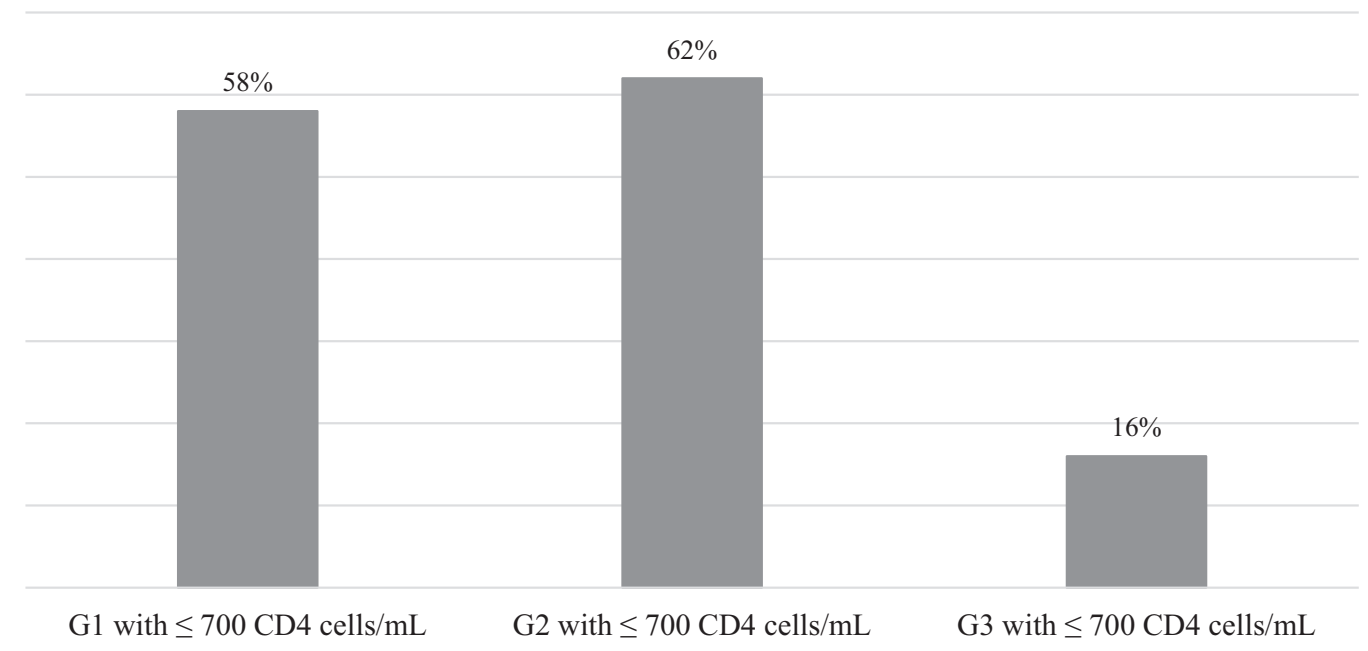

FIGURE 2. This graph shows the distribution of all eyes with intraocular pressure (IOP) $\leq 10 \mathrm{~mm} \mathrm{Hg}$ and also a CD4 $\leq 700$ cells/ $\mathrm{mm}^{3}$. The proportion among Group 1 and Group 2 are both significantly higher than Group $3(P<.01)$, but not significantly different from each other. Group $1(\mathrm{G} 1)$ = patients with human immunodeficiency virus (HIV) on highly active antiretroviral therapy (HAART); Group 2 (G2) = patients with HIV not on HAART; and Group 3 (G3) = age- and sex-matched controls without HIV.

value for this model was 0.46 . Figure 2 demonstrates the distribution of patients with and IOP $\leq 10 \mathrm{~mm} \mathrm{Hg}$ who also have a CD4 count $\leq 700$ cells $/ \mathrm{mm}^{3}$.

\section{DISCUSSION}

PRIOR STUDIES HAVE DEMONSTRATED AN ASSOCIATION between positive HIV status and decreased IOP. Additionally, it has been hypothesized that immune recovery is associated with normalization of IOP compared with controls without HIV. This study was unique in that it allowed for a direct comparison of patients with HIV on or off HAART.

A greater proportion of patients with HIV both on and off HAART had an IOP $\leq 10 \mathrm{~mm} \mathrm{Hg}$ vs controls. In the linear regression model, a CD4 count of $<700$ cells $/ \mathrm{mm}^{3}$ contributed to a $2.1 \mathrm{~mm} \mathrm{Hg}$ decrease in intraocular pressure. The $\mathrm{R}^{2}$ value was only 0.19 in the linear regression model, indicating that all variables within this model account for $19 \%$ of the variability in IOP. It is worth noting that CD4 count was the only variable that significantly contributed to a reduced IOP in this model. Although it appears that $81 \%$ of the variation could be accounted for by variables that we have not measured, it is noteworthy that almost one fifth of the variation can be accounted for by a single variable. On logistic regression, low IOP was also associated with male sex; however, this may be an artifact owing to the disproportionate number of male subjects represented in the study. Additionally, patients with HIV were about 7 times more likely to have an IOP $\leq 10 \mathrm{~mm} \mathrm{Hg}$. Patients with a CD4 count $\leq 700$ cells $/ \mathrm{mm}^{3}$ were 13 times more likely to have an IOP $\leq 10 \mathrm{~mm} \mathrm{Hg}$. These relationships were independent of HAART status.

Causes of decreased IOP in patients with HIV are likely multifactorial, as hypothesized by previous authors. Prior studies have demonstrated decreased aqueous flow by fluorophotometry in these individuals. ${ }^{8}$ It has also been suggested that a low-grade cyclitis may contribute to a lowered IOP, ${ }^{12}$ which would explain why immune recovery is associated with a return to values matching those without HIV. HIV has been detected in aqueous fluid by reversetranscriptase PCR; however, it is not clear whether the presence of the virus within the aqueous directly impacts IOP. ${ }^{9}$ CMV retinitis has also specifically been implicated in lowered IOP and hypotony, which is thought to be related to increased aqueous flow directly across damaged retina, ${ }^{8}$ as well as ciliary body atrophy. ${ }^{12}$ Administration of cidofovir for treatment of CMV retinitis is associated with hypotony ${ }^{10,11}$; however, in our study patients with history of CMV retinitis were excluded so as to control for this. The fact that lower IOP was found among those with a decreased CD4 count, independent of their HAART status, is suggestive that either immune suppression or active HIV infection contributes to lower IOP, rather than the direct effect of antiretroviral therapy. 
There were several limitations to this study. This was a retrospective cross-sectional study, which can limit data collection owing to missing values and long-term followup. A longitudinal study might provide a more precise representation of patients' IOP and how CD4 count and viral load may play a role over time. Additionally, the majority of patients seen in the general eye clinic at our academic center are black men; therefore the findings may not be generalizable to all populations. Further studies are needed to verify the relationship between CD4 count and IOP. The control group for this study included patients who were receiving chemotherapy for various types of malignancies by the hematology/oncology service. Although this provided an opportunity to compare CD4 counts to those of patients without HIV, it can be argued that the control group does not represent our study population. However, when stratifying for these patients in our descriptive statistical representation, there was no major differences within controls. Given that CD4 count and IOP within this group approach previously measured mean values, the impact this had on skewing our results is likely minimal. Furthermore, these patients represent a convenience sample, a commonly used method when selecting controls. ${ }^{15-17}$ Another limitation is that patients with glaucoma or who were diagnosed as glaucoma suspect were not studied to avoid confounding variables such as prior or current IOP-lowering therapy. Before these populations are studied, the correlation between CD4 count and IOP must become better understood in a healthy population. Further studies of populations with glaucoma and HIV as comorbid conditions are needed. Lastly, specific HAART regimens were not studied. Owing to the variety of HAART regimens our patients were on, as well as scenarios where HAART regimens had recently been changed prior to their eye examination, analyzing any specific medication or combination of medications was beyond the scope of this study. Although this should not significantly impact our data if IOP is more directly related to immune recovery, it limits our ability to identify a specific medication or class of medications that could have an IOP-lowering effect. Further studies on specific medications or medication classes are needed.

HAART is a well-established therapy for patients with HIV, and it has become increasingly important to understand how HIV and antiretroviral therapy affect chronic medical conditions, including issues related to visual health. Understanding how IOP is affected both by HIV and antiretroviral therapy will aid in the management of patients with glaucoma and related entities. Future research on specific medication regimens and their impact on IOP could be valuable in managing the visual health in patients with HIV. Additionally, understanding the association between immune suppression and IOP may be useful in the development of future medications designed for treating glaucoma. Further studies on patients with HIV and decreased CD4 counts will provide an opportunity to explore this relationship. Though the literature supporting the link between lower IOP and HIV continues to grow, further research is needed on the subpopulation of patients with the diagnosis of glaucoma.

FUNDING/SUPPORT: NO FUNDING OR GRANT SUPPORT. FINANCIAL DISCLOSURES: THE FOLLOWING AUTHORS HAVE NO financial disclosures: Matthew T. Young, Rakhi T. Melvani, Faraaz A. Khan, Puneet S. Braich, and Surbhi Bansal. All authors attest that they meet the current ICMJE criteria for authorship.

The authors would like to acknowledge the tireless efforts of Meagan Sok (Research Coordinator, Virginia Commonwealth University, Richmond, Virginia), who has been an invaluable resource as our department's research coordinator. We appreciate the appraisal/critique of our work from our colleagues, Dr Vikram Brar (Professor, Department of Ophthalmology, Virginia Commonwealth University, Richmond, Virginia, USA) and Dr Christopher Leffler (Assistant Professor, Department of Ophthalmology, Virginia Commonwealth University, Richmond, Virginia, USA).

\section{REFERENCES}

1. Centers for Disease Control and Prevention. Today's HIV/ AIDS epidemic. February 2016. Available at http://www. cdc.gov/nchhstp/newsroom/docs/factsheets/todaysepidemic508.pdf. Accessed June 15, 2016.

2. Bhatti A, Usman M, Kandi V. Current scenario of HIV/AIDS, treatment options, and major challenges with compliance to antiretroviral therapy. Cureus 2016; 8(3):e515.

3. Braich PS, Almeida DR, Hollands S, Coleman MT. Effects of pictograms in educating 3 distinct low-literacy populations on the use of postoperative cataract medication. Can J Ophthalmol 2011;46(3):276-281.
4. Braich PS, Lal V, Hollands S, Almeida DR. Burden and depression in the caregivers of blind patients in India. Ophthalmology 2012;119(2):221-226.

5. Braich PS, Jackson M, Knohl SJ, Bhoiwala D, Gandham SB, Almeida D. Burden and depression in caregivers of blind patients in New York State. Ophthalmic Epidemiol 2016; 23(3):162-170.

6. Nasoodi A, Lim L, Al-Ani A, Quah S, Dinsmore W. What you can see in your patient's eyes? Review of ocular manifestations of HIV in HAART era. Int J STD AIDS 2008;19(1):4-11.

7. Arevalo J, Munguia D, Faber D, et al. Correlation between intraocular pressure and $\mathrm{CD} 4+\mathrm{T}$-lymphocyte counts in patients with human immunodeficiency virus with and without cytomegalovirus retinitis. Am J Ophthalmol 1996;122(1):91-96. 
8. Banker A, Arevalo J, Azen S, et al. Fluorophotometry in patients with human immunodeficiency virus with and without cytomegalovirus retinitis. Ophthalmology 1999;106(3):590-593.

9. Hsu W, Chiou S, Chen S, et al. The HIV RNA levels of plasma and ocular fluids in AIDS patients with ophthalmic infections. Ophthalmologica 2004;218(5):328-332.

10. Banker A, Arevalo J, Munguia D, et al. Intraocular pressure and aqueous humor dynamics in patients with AIDS treated with intravitreal cidofovir (HPMPC) for cytomegalovirus retinitis. Am J Ophthalmol 1997;124(2):168-180.

11. Davis JL, Taskintuna I, Freeman WR, Weinberg DV, Feuer WJ, Leonard RE. Iritis and hypotony after treatment with intravenous cidofovir for cytomegalovirus retinitis. Arch Ophthalmol 1997;115(6):733.

12. Park R, Mudumbai R, Chen P. Intraocular pressure in patients with human immunodeficiency virus and treated with highly active antiretroviral therapy. Am J Ophthalmol 2003;136(2): 360-361.
13. Kozak I, LaBree L, Azen SP, Cheng L, Reagan NL, Freeman WR. Long-term study of intraocular pressure changes in patients with human immunodeficiency virus treated with highly active antiretroviral therapy. Ophthalmology 2006;113(3):451-455.

14. Sit A, McLaren J. Measurement of episcleral venous pressure. Exp Eye Res 2011;93(3):291-298.

15. Haripriya A, Chang DF, Namburar S, Smita A, Ravindran RD. Efficacy of intracameral moxifloxacin endophthalmitis prophylaxis at Aravind Eye Hospital. Ophthalmology 2016;123(2):302-308.

16. Zhu X, He W, Sun X, Dai J, Lu Y. Fixation stability and refractive error after cataract surgery in highly myopic eyes. Am J Ophthalmol 2016;169:89-94.

17. Chen YH, Lien R, Chiang MF, et al. Outer retinal structural alternation and segmentation errors in optical coherence tomography imaging in patients with a history of retinopathy of prematurity. Am J Ophthalmol 2016;166:169-180. 